\title{
Effects of brinzolamide vs timolol as an adjunctive medication to latanoprost on circadian intraocular pressure control in primary open-angle glaucoma Japanese patients
}

This article was published in the following Dove Press journal:

Clinical Ophthalmology

2 September 2009

Number of times this article has been viewed

\author{
Makoto Ishikawa ${ }^{1,2}$ \\ Takeshi Yoshitomi' \\ 'Department of Ophthalmology, Akita \\ University Faculty of Medicine, Akita, \\ Japan; ${ }^{2}$ Department of Ophthalmology, \\ Ogachi Central Hospital, Akita, Japan
}

Purpose: To study the effect of the concomitant use of brinzolamide and latanoprost on the 24-hour variation in intraocular pressure (IOP) in primary open-angle glaucoma (POAG) patients first treated with timolol and latanoprost.

Methods: We studied 30 eyes from 30 POAG patients previously treated with latanoprost monotherapy. After a washout of four weeks in both eyes, all patients were treated with $0.5 \%$ timolol and latanoprost. Three months after the initiation of treatment with timolol and latanoprost, the 24-hour IOP variation was measured. Thereafter, all patients were treated with concomitant $1 \%$ brinzolamide and latanoprost. Three months after changing the therapeutic regimen, the 24-hour IOP variation was measured a second time. Latanoprost was administered once a day, and timolol and brinzolamide were twice a day. IOP was measured with a noncontact tomometer.

Results: On treatment with brinzolamide and latanoprost, a significant decrease in IOP compared to timolol and latanoprost was observed at all time points except at 3 PM and 6 PM. As a group, the patients had a significantly lower diurnal mean IOP and nocturnal mean IOP during treatment with brinzolamide and latanoprost than with timolol and latanoprost.

Conclusions: Treatment of POAG with a combination of brinzolamide and latanoprost demonstrated improved hypotensive effects compared with timolol and latanoprost during a 24-hour period.

Keywords: circadian intraocular pressure, adverse effects, timolol, brinzolamide

\section{Introduction}

The most important risk factor in glaucoma is poorly controlled ocular hypertension. ${ }^{1}$ Therefore, a therapy that lowers intraocular pressure (IOP) is the most reliable approach for glaucoma.

Timolol, a relatively nonselective $\beta$-blocker, lowers IOP by suppressing the production of aqueous humor and is considered to be among the most effective glaucoma medications developed over the past 20 years. However, it is likely that timolol may cause adverse reactions in the cardiovascular and respiratory systems, ${ }^{2,3}$ and hence, a carefully obtained medical history is necessary to identify any predisposing condition. $^{4}$

Prostaglandin F2 $\alpha$ analogs (PGA) are a class of IOP-lowering medications that reduce IOP by increasing the aqueous humor outflow rate via the uveoscleral route. ${ }^{5}$ The PGA latanoprost has a favorable IOP-lowering effect and causes no serious systemic adverse reactions; consequently, it has been widely used as a first-line glaucoma
Correspondence: Makoto Ishikawa Department of Ophthalmology, Akita University Faculty of Medicine, Hondo I-I-I, Akita 0 I0-8543, Japan

Tel $+8 \mathrm{I}$ I 8834 I I I I

Fax +81188362621

Email mako@med.akita-u.ac.jp 
medication. ${ }^{6}$ However, PGA has several local side effects such as iris pigmentation, ${ }^{7}$ poliosis, ${ }^{8}$ eyelid pigmentation, ${ }^{9}$ etc. Occasionally, patients cannot attain their target IOP and either switch to another PGA and/or require adjunctive therapy. ${ }^{10}$ Unfixed $^{8}$ or fixed combinations ${ }^{11,12}$ of latanoprost and timolol have been demonstrated to effectively lower IOP.

Brinzolamide is a more recently developed carbonic anhydrase inhibitor. ${ }^{13-15}$ The effects of coadministration of brinzolamide with latanoprost have been explored in few studies. ${ }^{16-20}$ Brinzolamide lowers IOP by suppressing the production of aqueous humor. Indeed, brinzolamide monotherapy appears to have a weaker IOP-lowering effect than $\beta$-blocker monotherapy $;{ }^{17}$ however, brinzolamide is expected to exert a further IOP-lowering effect when added to a PGA, like other carbonic anhydrase inhibitors. ${ }^{21,22}$ Nakamoto and Yasuda $^{23}$ reported that when single-agent latanoprost was compared to concomitant treatment with brinzolamide and latanoprost, the combination therapy exerted a greater nocturnal IOP-lowering effect. Additionally, it has been reported that the concomitant use of PGA $0.004 \%$ travoprost and $0.1 \%$ brinzolamide is superior in its IOP-lowering effect to the fixed combination (Xalacom; Pfizer, New York, NY, USA) of $0.005 \%$ latanoprost and $0.5 \%$ timolol. $^{22}$

In this single-arm study, patients with primary open-angle glaucoma (POAG) were coadministered timolol and latanoprost for three months, after which the therapy was changed to brinzolamide and latanoprost in order to investigate potential changes in circadian IOP variation. In addition, the cardiovascular safety of these two combination regimens was also investigated.

\section{Patients and methods}

\section{Inclusion and exclusion criteria}

Patients with POAG receiving outpatient care at the Department of Ophthalmology, Ogachi Central Hospital, Akita, Japan, were enrolled. The study was carried out in accordance with the World Medical Association's Declaration of Helsinki and was approved by the ethical review board at Ogachi Central Hospital.

Patients were selected from those who had latanoprost monotherapy for over three months. Patients were required to provide written informed consent; have a typical glaucomatous optic disc finding with a corresponding visual field defect in both eyes; and lack any eye, nasal sinus, or systemic disease affecting the optic nerve. Additional exclusion criteria included heart disease, respiratory disease, past history of renal disease, past history of serious corneal lesion or uveitis, past history of intraocular surgery or laser treatment, systemic use of a carbonic anhydrase inhibitor or $\beta$-blocker, corneal endothelial cell count of less than 1,500 cells $/ \mathrm{mm}^{2}$, and ineligibility to participate in this study as judged by the investigators. Ocular hypertension of greater than $25 \mathrm{mmHg}$ while using latanoprost monotherapy was also excluded from this study in order to avoid the risk of further elevation of IOP.

\section{Study design}

Patients had a four-week washout period, in which they discontinued latanoprost use. Patients then topically applied $0.5 \%$ timolol to both eyes twice daily (8 AM and $8 \mathrm{PM}$ ) and latanoprost once daily (8 PM). Patients were instructed to use forced eyelid closure for three minutes, and keep a time interval of five minutes between topical applications when applying the drugs at 8 PM. All patients visited the hospital every four weeks. A questionnaire asking about current use of eye drops was distributed to all patients at the time of their regular clinical visits, and their adherence to medication was evaluated. Three months after the start of treatment, the patients were hospitalized, during which their 24-hour circadian IOP variation was measured as follows: IOP was measured three times at each time point in the sitting position with a noncontact tonometer (P ULSAIR 2000; Keeler Co, Windsor, England) in three-hour intervals for a total of eight times a day (6 AM, 9 AM, 12 PM, 3 PM, 6 PM, 9 PM, 12 AM, 3 AM). At night, patients were awakened and allowed to relax for 10 minutes, and then IOP was measured with the patient sitting on the bed. According to a previous report, ${ }^{24}$ measurement was calculated three times and averaged if the difference in IOP measurement was $3 \mathrm{mmHg}$ or less. When the difference was greater than $3 \mathrm{mmHg}$, the IOP was measured until the difference in three consecutive values was $3 \mathrm{mmHg}$ or less.

Immediately following this series of measurements, $1 \%$ brinzolamide was substituted for timolol, and co-administration with latanoprost was continued for three months. Brinzolamide was applied to both eyes twice daily (8 AM and $8 \mathrm{PM}$ ) and latanoprost once daily (8 PM). As before, the patients were instructed to use forced eyelid closure for three minutes, along with a five-minute time interval between topical applications when applying the drugs at 8 PM. After three months of treatment, the patients were hospitalized a second time, during which their circadian IOP variation was measured again. Blood pressure and pulse rate were measured in triplicate between 9 AM and 10 AM on each hospitalization day.

\section{Statistical analysis}

From IOP measurements during hospitalization, the following outcomes were calculated: (1) 24-hour mean IOP 
(mean value of IOP at all time points), (2) diurnal mean IOP (mean value of IOP at 9 AM, 12 PM, and 3 PM), and (3) nocturnal IOP (mean value of IOP at 9 PM, 12 AM, and 3 AM). Percent reduction in IOP was calculated by using the following formula:

$$
\begin{aligned}
& \text { Percent reduction in IOP }=[(\text { latanoprost }+ \text { timolol IOP } \\
& \quad-\text { latanoprost }+ \text { brinzolamide } \mathrm{IOP}) / \text { latanoprost } \\
& + \text { timolol IOP }] \times 100
\end{aligned}
$$

Systolic blood pressure, diastolic blood pressure, mean blood pressure, and pulse rate were compared before and after the transition from timolol to brinzolamide.

Statistical analyses using the right eye of each patient were conducted using two-sided paired $t$-test with a significance level of $5 \%$.

\section{Glaucoma criteria}

Glaucoma diagnosis was based on optic disc appearance, including cup-to-disc ratio; rim width; nerve fiber layer defect; the results of the Humphrey Field Analyzer examination; and clinical records from screening and definitive examinations. The criteria for glaucoma diagnosis were based on the criteria of previous population studies, ${ }^{25}$ described in Table 1. First, when the vertical cup-to-disc ratio of the optic nerve head was 0.7 or more; or the rim width at the superior portion (the 11 to 1 o'clock position) or inferior portion (the 5 to 7 o'clock position) was 0.1 or less of disc diameter; or the difference in the vertical cup-to-disc ratio was 0.2 or more between both eyes; or a nerve fiber layer defect was found - and the Hemifield-based visual field abnormality was compatible with optic disc appearance or nerve fiber layer defect - the eye was diagnosed with glaucoma (Category 1). Next, when the vertical cup-to-disc ratio was 0.9 or more; or the rim width at the superior portion (the 11 to $1 \mathrm{o}$ 'clock position) or inferior portion (the 5 to 7 o'clock position) 0.05 or less; or the difference in the vertical cup-to-disc ratio was 0.3 or more between both eyes - when the visual field test result was not reliable or available - a diagnosis was obtained of glaucoma (Category 2 ). When the eye with the cup-to-disc ratio was 0.7 or more but less than 0.9 ; or the rim width at the superior portion (the 11 to 1 o'clock position) or inferior portion (the 5 to 7 o'clock position) was 0.1 or less but more than 0.05 of the disc diameter; or the difference of the vertical cup-to-disc ratio was 0.2 or more but less than 0.3 between both eyes; or a nerve fiber layer defect was found - and the visual field test was not reliable or available or did not show compatible Hemifield-based defect - the eye was diagnosed as being glaucoma suspect (Glaucoma suspect). In the definitive diagnosis, anomalous discs, including tilted discs, were carefully excluded.

\section{Results}

Thirty patients were enrolled in this study. Fifty percent $(n=15)$ of the patients were male. The mean age of the total patient population was $70.2 \pm 10.2$ years old. No patients discontinued treatment or withdrew from the study. Prior to enrollment, all participants were treated with $0.005 \%$ latanoprost monotherapy, which was topically applied to both eyes once daily at night for $5.5 \pm 2.0$ months; it produced $20 \%-33 \%$ reduction in IOP (the mean IOP range was $16.8 \pm 3.2 \mathrm{mmHg}$ ). The minimum untreated IOP was $17 \mathrm{mmHg}$, and the average untreated IOP was $18.9 \pm 5.6 \mathrm{mmHg}$. The visual field mean deviation (MD) at enrollment was $-4.2 \pm 3.2 \mathrm{~dB}$ on the Humphrey Field Analyzer, Center 30-2 Program.

IOP was analyzed using the data from the right eye of the enrolled patients. The comparison of mean IOP

Table I The criteria for primary open-angle glaucoma diagnosis

\section{Category I}

The vertical cup-to-disc ratio of the optic nerve head is 0.7 or more, or the rim width at the superior portion (II-I hours) or the inferior portion (5-7 hours) is 0.1 or less of the disc diameter, or the difference of the vertical cup-to-disc ratio is 0.2 or more between both eyes, or a nerve fiber layer defect is found, and the hemifield-based visual field abnormality is compatible with optic disc appearance or nerve fiber layer defect

\section{Category 2}

When the visual field test result is not reliable or available, the cup-to-disc ratio of the optic nerve head is 0.9 or more, or the rim width at the superior portion ( $1 \mathrm{I}-\mathrm{I}$ hours) or the inferior portion (5-7 hours) is 0.05 or less of the disc diameter, or the difference of the vertical cup-to-disc ratio is 0.3 or more between both eyes

\section{Glaucoma suspect}

When the cup-to-disc ratio of the optic nerve head is 0.7 or more but less than 0.9 , or the rim width at the superior portion (II-I hours) or the inferior portion (5-7 hours) is 0.1 or less but more than 0.05 of the disc diameter, or the difference of the vertical cup-to-disc ratio is 0.2 or more but less than 0.3 between both eyes, or the nerve fiber layer defect is found, and the visual field test is not reliable or available or does not show hemifield-based compatible defect, the eye is diagnosed with suspected glaucoma 
between treatment regimens at each time point showed that a significant IOP reduction was observed after the transition to brinzolamide and latanoprost at all time points except at $3 \mathrm{PM}$ and $6 \mathrm{PM}$ (Figure 1, $P<0.01$ ). The 24-hour mean IOP with timolol and latanoprost was $12.6 \pm 2.4 \mathrm{mmHg}$ compared to $11.9 \pm 2.5 \mathrm{mmHg}$ after the change in treatment to brinzolamide and latanoprost. This represents a statistically significant difference (Figure 2, $P<0.01$ ) that translated into a $5.8 \% \pm 1.5 \%$ reduction in IOP. Diurnal mean IOP was $12.6 \pm 2.3 \mathrm{mmHg}$ before the transition, and $11.8 \pm 2.3 \mathrm{mmHg}$ after the transition (Figure 2, $P<0.05$ ) for a $7.3 \% \pm 1.9 \%$ reduction in IOP. The nocturnal mean IOP was $13.1 \pm 3.4 \mathrm{mmHg}$ before the transition and $11.7 \pm 3.1 \mathrm{mmHg}$ after the transition, showing a statistically significant reduction in IOP (Figure 2, $P<0.001$ ) of $9.6 \% \pm 1.9 \%$. The maximum mean IOP was $15.0 \pm 3.9 \mathrm{mmHg}$ with timolol and latanoprost therapy and $14.1 \pm 4.2 \mathrm{mmHg}$ with brinzolamide and latanoprost therapy, showing a significant reduction in IOP of $6.1 \% \pm 2.3 \%$ (Figure $3, P<0.05$ ). The minimum mean IOP was $10.5 \pm 1.9 \mathrm{mmHg}$ before the transition and $10.2 \pm 1.7 \mathrm{mmHg}$ after changing the regimen, showing no significant difference between the two regimens (Figure 3 ). The IOP range was $4.3 \pm 2.4 \mathrm{mmHg}$ before the change from timolol to brinzolamide and $3.9 \pm 2.5 \mathrm{mmHg}$ after the transition, showing no statistically significant difference (Figure 3).

Based on the questionnaire on the use of eye drops, patient adherence was calculated to be least $90 \%$ in all cases for each medication.

No statistically significant difference in systolic blood pressure, diastolic blood pressure, or mean blood pressure was observed between the treatment regimens (Table 2). The pulse rate was significantly higher after the transition to brinzolamide and latanoprost therapy $(65.7 \pm 5.7$ vs $72.9 \pm 6.7$ beats/minute, $P<0.05$; Table 2).

Adverse events observed during the study are presented in Table 3. Mild conjunctival hyperemia (one patient) and corneal epithelial disorder (one patient) were observed while taking timolol and latanoprost, but these symptoms disappeared after transitioning to brinzolamide and latanoprost. Taste perversion (one patient) was observed after the transition to brinzolamide and latanoprost, but it was present only transiently and required no treatment.

\section{Discussion}

Concomitant treatment with timolol and latanoprost was conducted for three months in patients with open-angle glaucoma, followed by concomitant treatment with brinzolamide

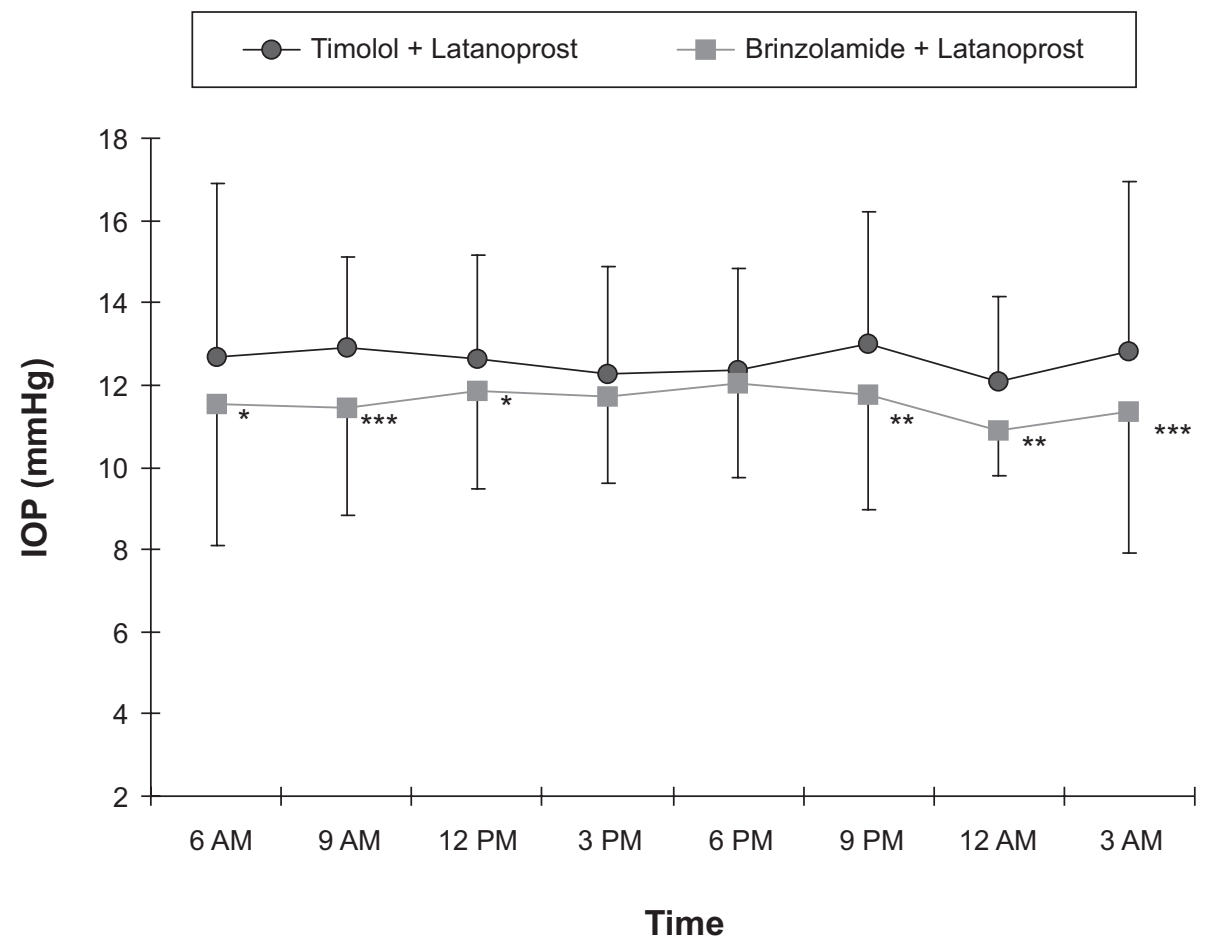

Figure I Comparison of mean intraocular pressure levels (millimeters of mercury) for timolol and latanoprost versus brinzolamide and latanoprost across a 24-hour time period $(n=30)$.

Notes: $* \mathrm{P}<0.05$, **P $<0.01$, ${ }^{* * * P}<0.001$, mean \pm SE (paired $t$-test).

Abbreviations: IOP, intraocular pressure; SE, standard error. 


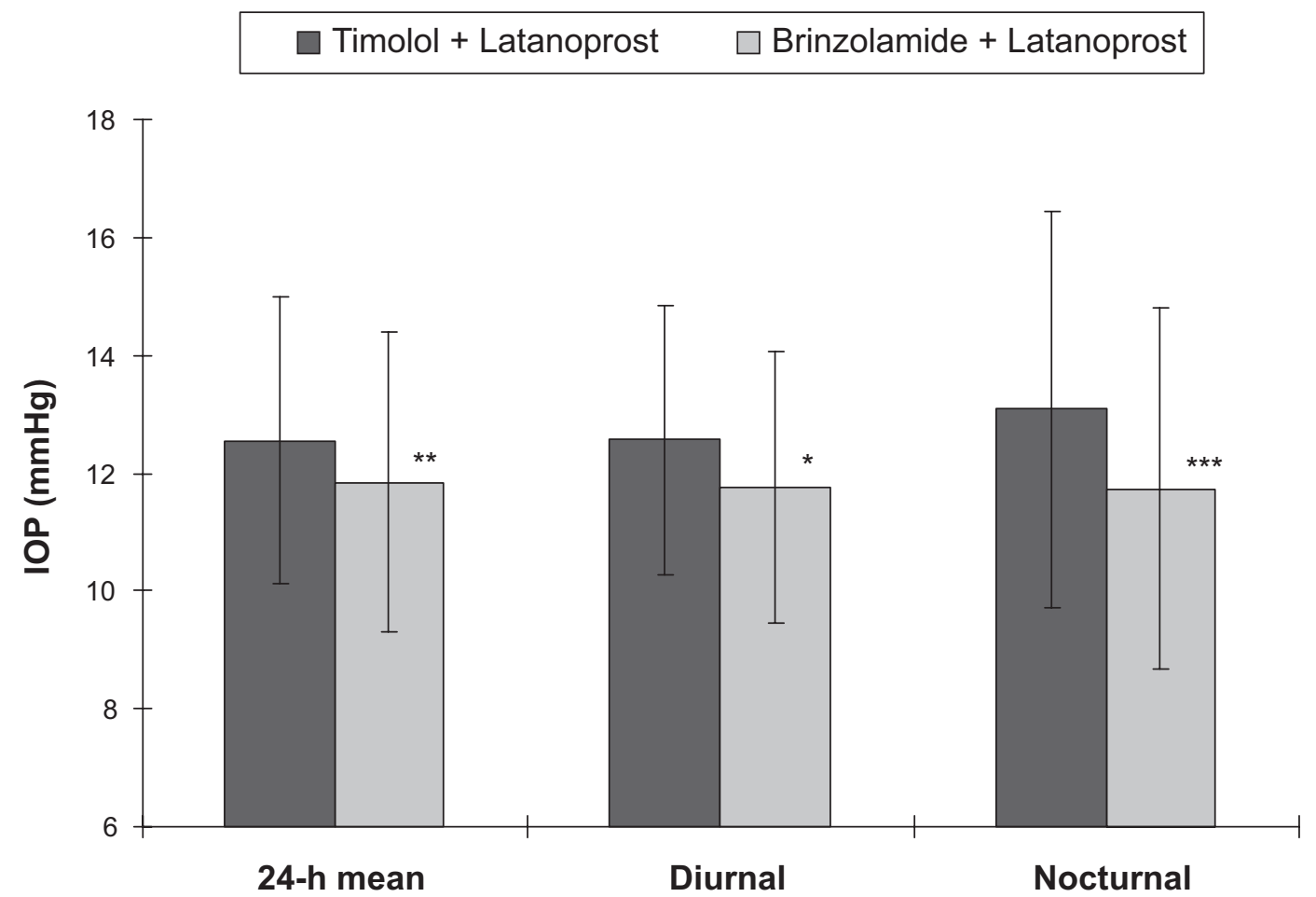

Figure 2 Comparison of 24-hour mean IOP (averaged across all time points), diurnal mean IOP ( 9 AM, 12 PM, and 3 PM), and nocturnal mean IOP ( 9 PM, I2 AM, and 3 AM) for timolol and latanoprost versus brinzolamide and latanoprost $(n=30)$.

Notes: $* P<0.05, * * P<0.01$, ***P $<0.001$, mean $\pm S E$ (paired $t$-test).

Abbreviations: IOP, intraocular pressure; SE, standard error.

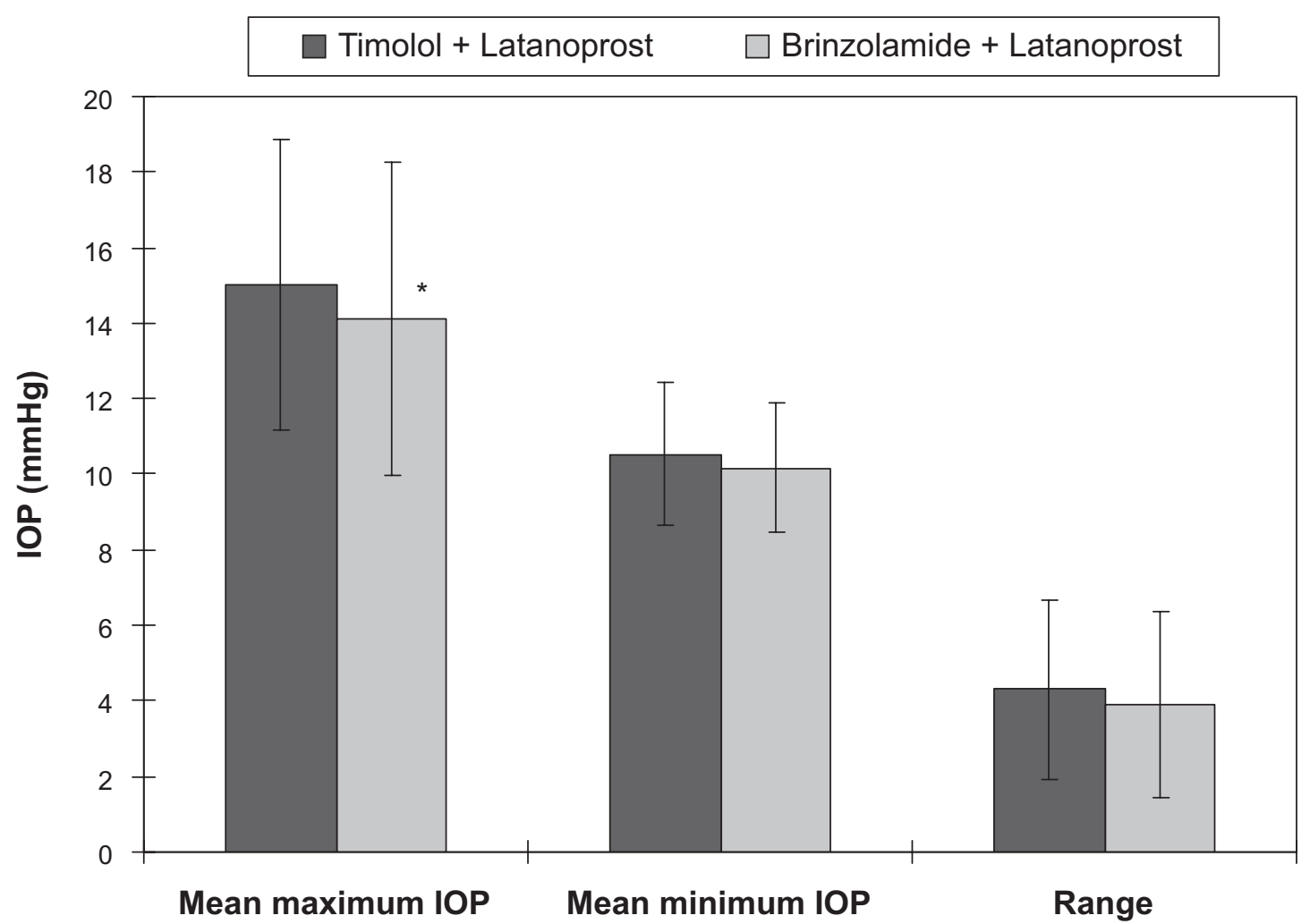

Figure 3 Comparison of mean maximum IOP, mean minimum IOP, and mean IOP range for eyes receiving timolol and latanoprost versus brinzolamide and latanoprost $(\mathrm{n}=30$ ). Notes: $* P<0.05$, mean \pm SE (paired $t$-test).

Abbreviations: IOP, intraocular pressure; SE, standard error. 
Table 2 Comparison of blood pressure and pulse rate before and after changing treatment

\begin{tabular}{llc}
\hline Blood pressure $(\mathbf{m m H g})$ & $\begin{array}{l}\text { Timolol } \\
\text { + Latanoprost }\end{array}$ & $\begin{array}{l}\text { Brinzolamide } \\
\text { + Latanoprost }\end{array}$ \\
\hline Systolic & $128.5 \pm 15.6$ & $130.1 \pm 14.7$ \\
Diastolic & $78.1 \pm 7.9$ & $79.1 \pm 12.6$ \\
Mean & $94.5 \pm 13.4$ & $95.1 \pm 11.9$ \\
Pulse rate (beat $/ \mathrm{min})$ & $65.7 \pm 5.7$ & $72.9 \pm 6.7^{*}$ \\
\hline
\end{tabular}

Note: $* p<0.05$ (paired $t$-test)

and latanoprost for three months, in a topical medication transition study. When treatment was changed from timolol and latanoprost to brinzolamide and latanoprost, the most significant IOP-lowering effect was documented at night. The mean IOP difference was also statistically significant. These results may indicate that brinzolamide provides a more sustained IOP-lowering effect than timolol throughout a 24-hour period when added to latanoprost. Since lowering IOP reduces the risk of glaucoma onset and progression, it is clinically meaningful for individual patients. In contrast, timolol lowers office-hour IOP, but it has little IOP-lowering effect at night. These observations are consistent with a previous report showing different IOP-lowering effect of brinzolamide and timolol used as monotherapy ${ }^{26}$ or add-on therapy to latanoprost. ${ }^{27}$

Control of nocturnal IOP is important for progression of visual field defects in glaucoma. ${ }^{28}$ However, the precise mechanism of IOP regulation by brinzolamide during the nocturnal period is not fully understood. Although brinzolamide caused a smaller reduction in aqueous humor formation during the nocturnal period than during the diurnal period, ${ }^{15}$ brinzolamide significantly reduced the nocturnal IOP. ${ }^{28}$ The reason for the present difference in nocturnal IOP-lowering effect between the two treatment regimens can be explained by the fact that timolol does not produce a nocturnal IOP-lowering effect. ${ }^{14,29}$

Table 3 Adverse events observed during the study

\begin{tabular}{|c|c|c|}
\hline & $\begin{array}{l}\text { Timolol + } \\
\text { Latanoprost }\end{array}$ & $\begin{array}{c}\text { Brinzolamide + } \\
\text { Latanoprost }\end{array}$ \\
\hline \multicolumn{3}{|l|}{ Ocular adverse reactions } \\
\hline Conjunctival hyperemia & 1 & 0 \\
\hline Corneal epithelial damage & 1 & 0 \\
\hline \multicolumn{3}{|c|}{ Systemic adverse reactions } \\
\hline Taste perversion & 0 & 1 \\
\hline
\end{tabular}

Although brinzolamide produced superior IOP-lowering results compared to timolol in this study, we must discuss the following limitation of the present study design. The patients were not randomized into treatment with either brinzolamide and latanoprost or timolol and latanoprost. Thus, the treatment sequence or underlying changes in the disease over time could have affected the results of this study.

In recent years, it has been suggested that glaucomatous optic neuropathy may be caused by a reduction in blood flow in the optic disc because of nocturnal hypotension and heart rate decrease. ${ }^{30}$ Hayreh and colleagues ${ }^{31}$ reported that when a $\beta$-blocker was topically applied to glaucoma patients, nocturnal blood pressure and heart rate were reduced, thereby deteriorating the visual field. For this reason, it may be desirable to use drugs that have minimal effects on the cardiovascular system of glaucoma patients. The merits of brinzolamide include fewer ocular adverse events $^{32}$ and no serious systemic adverse reactions. ${ }^{23}$ A previous study has shown that, in contrast to timolol, brinzolamide does not exert any suppressive effect on heart rate. ${ }^{33}$ Confocal laser Doppler flowmetry shows the positive blood flow effect of brinzolamide, which increases retinal oxygen saturation in patients with glaucoma. ${ }^{34}$ In the current investigation as well, treatment with brinzolamide and latanoprost produced no reduction in heart rate; rather, the mean pulse rate during timolol therapy was decreased compared to brinzolamide. Several population-based epidemiological studies ${ }^{35}$ have shown that ocular perfusion pressure (OPP) is a significant risk factor associated with glaucoma incidence. OPP is calculated as the following formula:

$$
\mathrm{OPP}=[\text { mean } \mathrm{BP} \times(2 / 3)-\mathrm{IOP}]
$$

In the present study, mean blood pressure, which is directly related to OPP, was similar in the two treatment regimens. However, timolol and latanoprost is considered to induce an increase in OPP because of concomitant significant reduction in IOP.

All three adverse reactions observed in the current study were mild and did not result in discontinuation of treatment. The frequency of ocular and systemic adverse reactions in this study was similar to those in previous reports. ${ }^{12,17,19,36}$

Although it is an applanation tonometer is commonly used, we measured the IOP with a noncontact tonometer in our study because of the inconvenience of our accommodation: the setting of a slit-lamp attached to 
applanation tonometer was located far from the bedside of our patients. We were afraid to allow the patients to walk for a distance, especially at midnight, because it is known that the circadian clock is responsible for the temporal organization of several functions, such as heart rate; body temperature; and hormonal release. ${ }^{37}$ Therefore, in the present study, we went to the patient bedside to measure the IOP by ourselves.

\section{Conclusions}

When taken together, the combination of brinzolamide and latanoprost demonstrated an improved hypotensive effect in open-angle glaucoma patients compared to timolol and latanoprost during a 24-hour period.

\section{Disclosures}

The authors report no conflicts of interest or financial support in this work.

\section{References}

1. Alward WC. Medical management of glaucoma. $N$ Engl J Med. 1998;339:1298-1307.

2. Van Buskirk EM, Fraunfelder FT. Ocular beta-blockers and systemic effects. Am J Ophthalmol. 1985;98:623-624.

3. Van Buskirk EM. Adverse reactions from timolol administration. Ophthalmology. 1980;87:447-450.

4. Lama PJ. Systemic adverse effects of beta-adrenergic blockers: an evidence-based assessment. Am J Ophthalmol. 2002;134: 749-760.

5. Toris CB, Camras CB, Yablonski ME. Effect of PhXA41. A new prostaglandin $\mathrm{F} 2$ alpha analog, on aqueous humor dynamics in human eye. Arch Ophthalmol. 1993;111:1351-1358.

6. Konstas AGP, Maltezos AC, Gandi S, Hudgins AC, Stewart WC. Comparison of 24-hour intraocular pressure reduction with two dosing regimens of latanoprost and timolol maleate in patients with primary open-angle glaucoma. Am J Ophthalmol. 1999;128:15-20.

7. Alm A, Grierson I, Shields MB. Side effects associated with prostaglandin analog therapy. Surv Ophthalmol. 2008;53:S93-S105.

8. Chen CS, Wells J, Craig JE. Topical prostaglandin F(2alpha) analog induced poliosis. Am J Ophthalmol. 2004;137:965-966.

9. Centofanti M, Oddone F, Chimenti S, Tanga L, Citarella L, Manni G. Prevention of dermatologic side effects of bimatoprost $0.03 \%$ topical therapy. Am J Ophthalmol. 2006;142:1059-1060.

10. Camras CB, Hedman K; the US Latanoprost Study Group. Rate of response to latanoprost or timolol in patients with ocular hypertension or glaucoma. J Glaucoma. 2003;12:466-469.

11. Higginbotham EJ, Diestelhorst M, Pfeiffer N, Rouland JF, Alm A. The efficacy and safety of unfixed and fixed combinations of latanoprost and other antiglaucoma medications. Surv Ophthalmol. 2002;47: S133-S140.

12. Hamacher T, Schinzel A, Scholzel-Klatt A, et al. Short term efficacy and safety in glaucoma patients chaaged to the latanoprost $0.005 \% /$ timolol maleate $0.5 \%$ fixed combination from monothrapies and adjunctive therapies. Br J Ophthalmol. 2004;88:1295-1298.

13. Friedenwald KS. Carbonic anhydrase inhibition and aqueous flow. Am J Ophthalmol. 1955;39:59-64.

14. Topper JE, Brubaker RF. Effects of timolol, epinrphrine, and acetazolamide on aqueous flow during sleep. Invest Ophthalmol Vis Sci. 1985;26:1315-1319.
15. Ingram CJ, Brubaker RF. Effect of brinzolamide and dorzolamide on aqueous humor flow in human eyes. Am J Ophthalmol. 1999; 128:292-296.

16. Tamer C, Oeksuez H. Circadian intraocular pressure control with dorzolamide versus timolol maleate add-on treatments in primary open-angle glaucoma patients using latanoprost. Ophthalmic Res. 2007;39:24-31.

17. Cvetkovic RS, Perry CM. Brinzolamide. A review of its use in the management of primary open-angle glaucoma and ocular hypertension. Drugs Aging. 2003;20:919-947.

18. Shoji N, Ogata N, Suyama H, et al. Intraocular pressure lowering effect of brimonidine $1.0 \%$ as adjunctive therapy to latanoprost $0.005 \%$ in patients with open angle glaucoma or ocular hypertension: an uncontrolled, open-label study. Curr Med Res Opin. 2005; 21:503-508.

19. Abe K, Kashiwagi K. Additive effect of brinzolamide on diurnal changes in intraocular pressure in latanoprost-treated eyes. Open Ophthalmol $J$. 2008;2:160-164.

20. Day DG, Hollander DA. Brimonidine purite $0.1 \%$ versus brinzolamide $1 \%$ as adjunctive therapy to latanoprost in patients with glaucoma or ocular hypertension. Curr Med Res Opin. 2008;5: $1435-1442$.

21. O'Connor DJ, Martone JF, Mead A. Additive intraocular pressure lowering effect of various medications with latanoprost. $\mathrm{Am} \mathrm{J}$ Ophthalmol. 2002;133:836-837.

22. Martinez-de-la-Casa JM, Castillo A, Garcia-Feijoo J, Martinez-Hernandez C, Fernandez-Vidal A, Garcia-Sanchez J. Concomitant administration of travoprost and brinzolamide versus fixed latanoprost/timolol combined therapy: three-month comparison of efficacy and safety. Curr Med Res Opin. 2004;20:1333-1339.

23. Nakamoto K, Yasuda N. Effect of concomitant use of latanoprost and brinzolamide on 24-hour variation of IOP in normal-tension glaucoma. J Glaucoma. 2007;16:352-357.

24. Hara T, Hara T, Tsuru T. Increase of peak intraocular pressure during sleep in reproduced diurnal changes by posture. Arch Ophthalmol. 2006;124:165-168.

25. Iwase A, Suzuki Y, Araie M, et al; The Tajimi Study Group, Japan Glaucoma Society. The prevalence of primary open-angle glaucoma in Japanese. Ophthalmology. 2004;111:1641-1648.

26. Orzalesi N, Rossetti L, Invernizzi T, Bottoli A, Autelitano A. Effect of timolol, latanoprost, and dorzolamide on circadian IOP in glaucoma or ocular hypertension. Invest Ophthalmol Vis Sci. 2000;41: 2566-2573.

27. Liu JH, Medeiros FA, Slight JR, Weinreb RN. Comparing diurnal and nocturnal effects of brinzolamide and timolol on intraocular pressure in patients receiving latanoprost monotherapy. Ophthalmology. 2009;116:449-454.

28. Follmann P, Palotás C, Süveges I, Petrovits A. Nocturnal blood pressure and intraocular pressure measurement in glaucoma patients and healthy controls. Int Ophthalmol. 1996-1997;20: 83-87.

29. Liu JH, Kripke DF, Weinreb RN. Comparison of the nocturnal effects of once-daily timolol and latanoprost on intraocular pressure. Am J Ophthalmol. 2004;138:389-395.

30. Hayreh SS, Podhajsky P, Zimmerman MB. Beta-blocker eyedrops and nocturnal arterial hypotension. Am J Ophthalmol. 1999;128: 301-309.

31. Hayreh SS, Podhajsky P, Zimmerman MB. Role of nocturnal arteral hypotension in optic nerve head ischemic disorders. Ophthalmologia. 1999;213:76-96.

32. Silver LH. Dose-response evaluation of the ocular hypotensive effect of brinzolamide ophthalmic suspension (Azopt). Brinzolamide Dose-Response Study Group. Surv Ophthalmol. 2000;44: $147-153$.

33. Miura K, Ito K, Okawa C, Sugimoto K, Matsunaga K, Uji Y. Comparison of ocular hypotensive effect and safety of brinzolamide and timolol added to latanoprost. J Glaucoma. 2008:17:233-237. 
34. Siesky B, Harris A, Cantor LB, et al. A comparative study of the effects of bronzolamide and doezolamide on retinal oxygen saturation and ocular microcieculation in patients with primary open-angle glaucoma. Br J Ophthalmol. 2008;92:500-504.

35. Leske MC, Wu SY, Hennis A, Hokkanen R, Nemesure B; BESs Study Group. Risk factors for incident open-angle glaucoma: the Barbados Eye Studies. Ophthalmology. 2008;115:85-93.
36. March WF, Ochsner KI. The long-term safety and efficacy of brinzolamide $1.0 \%$ (azopt) in patients with primary open-angle glaucoma or ocular hypertension. The Brinzolamide Long-Term Therapy Study Group. Am J Ophthalmol. 2000;129:136-143.

37. Herzog ED. Neurons and networks in daily rhythms. Nat Rev Neurosci. 2007;8:790-802.

\section{Publish your work in this journal}

Clinical Ophthalmology is an international, peer-reviewed journal covering all subspecialties within ophthalmology. Key topics include: Optometry; Visual science; Pharmacology and drug therapy in eye diseases; Basic Sciences; Primary and Secondary eye care; Patient Safety and Quality of Care Improvements. This journal is indexed on

\section{Dovepress}

PubMed Central and CAS, and is the official journal of The Society of Clinical Ophthalmology (SCO). The manuscript management system is completely online and includes a very quick and fair peer-review system, which is all easy to use. Visit http://www.dovepress.com/ testimonials.php to read real quotes from published authors. 